MATEC Web of Conferences 3, 01039 (2013)

DOI: $10.1051 /$ matecconf/20130301039

(C) Owned by the authors, published by EDP Sciences, 2013

\title{
Purification of artemisinin excerpt from Artemisia annua $L$
}

\author{
Z. Chemat-Djenni, and A. Sakhri \\ Chemical Engineering Laboratory, Department of Chemistry Industrie, Faculty of Technology, University Saad Dahlab, \\ 09000 Blida, Algeria
}

\begin{abstract}
The active pharmaceutical substance artemisinin found in Artemisia annua L. remains the most effective remedy against malaria. The objective of this work is the purification of the active ingredient through a natural matrix composed of clay sandwiched by aluminum. The purification process is carried by adsorption of the extracts on sodium type and bridged clay type. The XRD characterization of this material shows an increase in the basal distance of $10 \AA$ to $17 \AA$. This shows the success of the intercalation of aluminum polycation. We find a better purification of the extract when using aluminum bridged clay compared to sodium clay. The best performance of $80.64 \%$ adsorption is obtained at $40^{\circ} \mathrm{C}$ for the clay matrix bridged with aluminum complex.
\end{abstract}

\section{Introduction}

Artemisinin and its derivatives which are active through the peroxide bridge they possess are the best form of treatment against malaria. This disease is transmisse to humans by the bite of a female mosquito of the genus Anopheles infected by a parasite of the genus Plasmodium, is one of the most deadly infectious diseases. The specificity of artemisinin is in its natural origin, is extracted from the leaves of Artemisia annua L [1]. It considers the purification, a major problem of this active substance. We are interested in this work to develop a method of purification of artemisinin, while seeking optimal conditions of temperature and concentrations. Currently, a new family of microporous solids with controlled porosity, similar to zeolites called" pillars" Clays is widely developed and studied [2-4]. The synthesis of intercalated clays or crosslinked was reported the first time about 40 years ago. The increase in oil prices in 1973 has stimulated the search for new catalysts capable of increasing the yield of lighter fractions of crude oil. Intercalated clays are obtained from montmorillonite by inserting metal polycations in the interlayer, after calcination at $773 \mathrm{~K}$, the intercalated polycations, turning into pillars as clusters of metal oxides rigid and resistant, gives them strong high thermal stability. It is known that the choice of the precursor salt is essential in bridging these two-dimensional solid. Clays intercalated with the polycation structure hydroxyaluminique $\left[\mathrm{Al}_{13} \mathrm{O}_{4}(\mathrm{OH})_{24}\left(\mathrm{H}_{2} \mathrm{O}\right)_{12}\right]^{7+} \mathrm{Al}_{13}$ is noted interesting experimental model to the test of purification artémisénine.

\section{Experimental}

\subsection{Preparation of the catalysts based on clay}

The starting material is natural clay Maghia (West Algeria) is about $80 \%$ of montorillonite. It was made by homoionique exchange with cations $\mathrm{Na}^{+}$, it is noted MMT-Na and having a cation exchange capacity of 0.96 meq.g-1. The procedure for synthesis of the polymeraluminum hydroxy $\mathrm{Al}_{13}$ is titrated dropwise $(1.5 \mathrm{ml} /$ min) a solution of aluminum $\left(\mathrm{AlCl}_{3} \cdot 6 \mathrm{H}_{2} \mathrm{O}\right)$ defined concentration $(0.5 \mathrm{M}), \mathrm{NaOH}$ Concentration $(0.22 \mathrm{M})$ with an $\mathrm{OH} / \mathrm{Al}=2$ with vigorous stirring. The mixture is stirred for 3 hours and then left for 48 hours to aging of the polymer. The intercalating solution was then added dropwise $(2.4 \mathrm{ml} / \mathrm{min})$ to a suspension of $\mathrm{Na}$ montmorillonite MMT with an $\mathrm{Al} /$ clay $=5 \mathrm{mmol} / \mathrm{g}$ at $\mathrm{pH}=4.2$. The clay suspension thus obtained is filtered under vacuum, washed several times with distilled water, it is noted MMT-Al.

\subsection{Characterization of clays intercalated}

Clays intercalated structure was studied by XRD diffractometer PW 1800 by Philips with a copper cathode and a nickel filter using a copper line $(\lambda=1.5418 \AA)$. The technique of sample preparation method is oriented aggregates. It consists of placing a few drops of clay suspension on a glass object slide. This solution is allowed to evaporate for 24 hours at room temperature. Thus, the layers of montmorillonite (sodium or deck) preferentially settle their faces after 001 . We obtain a thin film of uniform thickness of clay stuck to the wall of the blade. 


\subsection{Method of purification of artemisinin}

The plant Artemisia annua L is dried ground and placed in a round bottom flask. The extraction solvent is added in a plant $/$ solvent ratio $=1 / 6 \mathrm{w} / \mathrm{v}(40$ grams of plant in $240 \mathrm{ml}$ solvent: hexane / ethyl acetate (95:5) V / V).

The crude extract artemisinin recovered is greenish color, indicating the possibility of the presence of chlorophyll. Given that the crude extract contains several chemical compounds and impurities. For this, we used adsorbents capable of retaining much of undesirable compounds. These adsorbents, namely sodium clay and pillared clay for aluminum, which were chosen due to their affinity adsorbents and their powers with a many compounds.

An amount of $0.2 \mathrm{~g}$ of the clay is added to the crude extract, the mixture is stirred for 60 minutes on a magnetic plate. After settling, the mixture was filtered. A desorption step ensures the recovery of part of the clay artemisinin trapped in order to show the effectiveness of the adsorbent. Clay adsorbed, we add $20 \mathrm{ml}$ of ethyl acetate and we precede to stir for 30 minutes. After filtration, the solution was concentrated under vacuum in a rotary evaporator. Finally, the solution is dissolved in 2 $\mathrm{ml}$ of acetonitrile and sent for analysis. Artemisinin, as most of the active ingredients, is determined and quantified by liquid chromatography with ultraviolet detector (HPLC / UV). The UV detector is recommended for samples containing artemisinin after purification, as in the case of a crude extract containing more impurities with high UV absorbance in the distance, it is very difficult to distinguish the peak of artemisinin is generally only observable [5]. In this regard, we present in both chromatograms before and after purification of artemisinin.

It should also be noted that artemisinin has no chromophores that absorb UV considerably, resulting in a very low detection limit. This led us to choose the wavelength of $220 \mathrm{~nm}$ to obtain consistent results.

\section{Results and Discussions}

\subsection{Characterization of pillared clay}

XRD results showed that the samples synthesized develop openings sheets $17 \AA$, which leads to a height of the pillars of the order of $6.5 \AA$. In the case of intercalation of aluminum, the expansion of the clay sheets and about $7 \AA$. This height corresponds approximately to the thickness of the polycationcontaining aluminum atoms and 13 of the formula $\left[\mathrm{Al}_{13} \mathrm{O}_{4}(\mathrm{OH})_{24}\left(\mathrm{H}_{2} \mathrm{O}\right)_{12}\right] 7+[6]$. We explain this phenomenon as follows: the intercalation of large metal oxide pillars between the clay sheets is achieved through their adsorption by cation exchange with the purified clay (MMT-Na) for which it manifests the maximum selectivity.

\subsection{Results of purification of Artemisinin by clays}

Standard solutions have used to calculate the concentrations of artemisinin in its various states; crude extract, purified extract and even that was retained by the adsorbent (desorption phase).

We took as adsorbents, respectively sodium clay and pillared clay with aluminum noted MMT-Na and MMT$\mathrm{Na}-\mathrm{Al}$. In both cases adsorption, we worked at $20{ }^{\circ} \mathrm{C}$ and $40{ }^{\circ} \mathrm{C}$ to see the effect of temperature on the adsorption, the overall results are shown in Table 1.

Table 1. Results of purification of artemisinin clays.

\begin{tabular}{|r|c|c|c|c|}
\hline adsorbents & $\begin{array}{c}\text { Artemisinin } \\
\text { Extract } \\
(\mathrm{mg})\end{array}$ & $\begin{array}{c}\text { Artemisinin } \\
\text { after } \\
\text { Adsorption } \\
(\mathrm{mg})\end{array}$ & $\begin{array}{c}\text { Artemisinin } \\
\text { retained in } \\
\text { the } \\
\text { adsorbent } \\
(\mathrm{mg})\end{array}$ & $\begin{array}{c}\text { \% of } \\
\text { purification } \\
\text { of } \\
\text { artemisinin }\end{array}$ \\
\hline $\begin{array}{r}\text { MMT-Na } \\
\left(20^{\circ} \mathrm{C}\right)\end{array}$ & 154.5 & 100.7 & 5.91 & 65.17 \\
\hline $\begin{array}{r}\mathrm{MMT}-\mathrm{Na} \\
\left(40^{\circ} \mathrm{C}\right)\end{array}$ & 154.5 & 115.82 & 4.49 & 74.96 \\
\hline $\begin{array}{r}\mathrm{MMT}-\mathrm{Al} \\
\left(20^{\circ} \mathrm{C}\right)\end{array}$ & 154.5 & 121.21 & 0.75 & 78.45 \\
\hline $\begin{array}{r}\mathrm{MMT}-\mathrm{Al} \\
\left(40^{\circ} \mathrm{C}\right)\end{array}$ & 154.5 & 124.64 & 0.64 & 80.67 \\
\hline
\end{tabular}

We note that the pillared clay purifies better extract compared to sodium clay. While the increase of temperature for the two arrays do not impact greatly on the purification of the extract. Artemisinin retained in the adsorbent and desorbed by acetonitril significantly lower in the aluminum pillared clay since it has pillars that can prevent good penetration of the drug artemisinin or the trap to inside and prevent desorbs.

\section{Conclusion}

The specificity of artemisinin is in its natural origin and the purification of the active ingredient remains a key issue for this remedy are the best form of treatment against malaria. Use of a natural matrix which is intercalated clay of aluminum for the purification of artemisinin showed purification rate of the order of $80.64 \%$ by intercalated clay in the aluminum temperature of $40{ }^{\circ} \mathrm{C}$.

\section{References}

1. G.A. Balint, Pharmacol Ther. 90261 (2001)

2. M.S. Tzou, UMI dissertation information service (1983)

3. J.A. Raussell-Colom and J.M. Serratosa, Chemistry of Clays and Clay Minerals, In: Newman, ACD, Ed. 371 (1987)

4. R.A. Schoonheydt, Studies in Surf. Sc. and Catal. 58 201 (1991)

5. A. Lapkin, A. Walker, B. Khambay, J. of Pharmaceutical and biomedical analysis 49908 (2009)

6. G. Fu, L.F. Nazar, A.D. Bain, Chem. Mater. 3 (1991) 